\title{
Bacterial Type I Toxins: Folding and Membrane Interactions
}

\author{
Sylvie Nonin-Lecomte ${ }^{1,+(\mathbb{D}) \text {, Laurence Fermon }}{ }^{2,+}$, Brice Felden $^{2, \pm(\mathbb{D})}$ and Marie-Laure Pinel-Marie $2, *(\mathbb{D})$ \\ 1 CiTCoM, CNRS, UMR 8038, Université de Paris, 93526 Paris, France; sylvie.nonin@u-paris.fr \\ 2 BRM (Bacterial Regulatory RNAs and Medicine), Inserm, UMR_S 1230, Université de Rennes 1, \\ 35000 Rennes, France; laurence.fermon@univ-rennes1.fr (L.F.); brice.felden@univ-rennes1.fr (B.F.) \\ * Correspondence: marie-laure.pinel@univ-rennes1.fr \\ + These authors contributed equally. \\ $\ddagger$ Deceased author.
}

check for

updates

Citation: Nonin-Lecomte, S.; Fermon, L.; Felden, B.; Pinel-Marie, M.-L. Bacterial Type I Toxins: Folding and Membrane Interactions. Toxins 2021, 13, 490. https://doi.org/ $10.3390 /$ toxins 13070490

Received: 7 June 2021

Accepted: 9 July 2021

Published: 14 July 2021

Corrected: 9 December 2021

Publisher's Note: MDPI stays neutral with regard to jurisdictional claims in published maps and institutional affiliations.

Copyright: (c) 2021 by the authors. Licensee MDPI, Basel, Switzerland. This article is an open access article distributed under the terms and conditions of the Creative Commons Attribution (CC BY) license (https:// creativecommons.org/licenses/by/ $4.0 /)$.

\begin{abstract}
Bacterial type I toxin-antitoxin systems are two-component genetic modules that encode a stable toxic protein whose ectopic overexpression can lead to growth arrest or cell death, and an unstable RNA antitoxin that inhibits toxin translation during growth. These systems are widely spread among bacterial species. Type I antitoxins are cis- or trans-encoded antisense small RNAs that interact with toxin-encoding mRNAs by pairing, thereby inhibiting toxin mRNA translation and/or inducing its degradation. Under environmental stress conditions, the up-regulation of the toxin and/or the antitoxin degradation by specific RNases promote toxin translation. Most type I toxins are small hydrophobic peptides with a predicted $\alpha$-helical transmembrane domain that induces membrane depolarization and/or permeabilization followed by a decrease of intracellular ATP, leading to plasmid maintenance, growth adaptation to environmental stresses, or persister cell formation. In this review, we describe the current state of the art on the folding and the membrane interactions of these membrane-associated type I toxins from either Gram-negative or Gram-positive bacteria and establish a chronology of their toxic effects on the bacterial cell. This review also includes novel structural results obtained by NMR concerning the sprG1-encoded membrane peptides that belong to the sprG1/SprF1 type I TA system expressed in Staphylococcus aureus and discusses the putative membrane interactions allowing the lysis of competing bacteria and host cells.
\end{abstract}

Keywords: toxin-antitoxin systems; type I toxins; mechanisms of action; membrane depolarization; membrane permeabilization; pore formation; nucleoid condensation; structure; folding

Key Contribution: This review describes the current state of the art on the folding and the membrane interactions of the membrane-associated type I toxins from bacteria and establishes a chronology of their toxic effects on the bacterial cell. It also includes novel structural results concerning the sprG1-encoded membrane peptides of the S. aureus sprG1/SprF1 type I TA system.

\section{Introduction}

Bacterial toxin-antitoxin (TA) systems are two-component genetic modules that encode a stable toxic protein, whose ectopic overexpression can lead to growth arrest or cell death, and an unstable antitoxin, which neutralizes toxin activity during bacterial growth [1] TA systems are widely spread among bacterial genomes, highlighting their potential importance [2]. They are classified into seven types depending on the antitoxin nature and its mode of action. While the toxins are always proteins, the antitoxins can be either non-coding RNAs (in type I and III systems) or small proteins (in types II, IV, V, VI, and VII). Antitoxins act by inhibiting toxin synthesis (in types I and V), sequestering the toxin (in types II and III), counteracting toxic activity (in type IV), promoting toxin degradation (in type VI), or by chemical modification of the toxin at a post-translational level (type VII) [3]. Recently, a novel type of TA system has been proposed in which both the toxin and the antitoxin are small RNAs [4]. Moreover, a type II/IV TA hybrid system has been 
described in which the DarG antitoxin interacts with the DarT toxin to inhibit its expression, but also acts on the target of DarT [5,6]. Antitoxins are unstable and more susceptible to degradation by ribonucleases or proteases than toxins, leaving toxins free to interfere with essential cellular functions such as replication, translation, or cell division [7]. In this review, we will focus exclusively on type I TA systems, characterized by a small antisense RNA that base-pairs with its cognate toxin-encoding messenger RNA (mRNA) to prevent the toxin synthesis under normal growth conditions. These systems are first predicted in the bacterial genomes through computational approaches [8]. However, only a few of them are experimentally characterized and mostly focused on E. coli.

Type I TA systems were initially identified on plasmids, where they ensure plasmid maintenance through a post-segregational killing (PSK) mechanism [9]. In this process, because of the antitoxin degradation, the plasmid loss results in the decrease of the antitoxin cell concentration and the killing of the plasmid-free cell by the stable toxin. Later on, homologues of known type I TA systems were discovered on bacterial chromosomes $[8,10]$. Although the biological role of chromosomal type I TA systems is still elusive, they can be involved in mobile genetic elements maintenance, growth adaptation to environmental stresses, or persister cells formation [11]. Persister cells represent a subpopulation of genetically identical and metabolically slow-growing bacteria that are tolerant to extremely high antibiotic doses after selection through repeated antibiotic therapy. They can result in treatment failure, relapse, and persistent bacterial infections [12].

Type I toxin expression is tightly controlled by RNA antitoxins and cis-encoded mRNA functional elements [13]. Most type I antitoxins are cis-acting antitoxins (e.g., hok/Sok, $b s r G / S R 4, s p r G / S p r F)$, meaning that the antitoxin and toxin loci overlap, resulting in a perfect pairing between the two RNAs. The trans-acting antitoxins (e.g., tisB/IstR1, $\operatorname{din} Q / \mathrm{AgrB}$ ) are located away from the toxin locus and share often limited sequence complementarities. The detailed description of the influence of the toxin expression on the RNA antitoxin regulation is not within the scope of our analysis. It has already been covered by two excellent reviews which describe type I antitoxin mode of action [13,14]. Toxinantitoxin RNA duplex formation can either result in toxin mRNA degradation or, more commonly, in toxin translation inhibition, or in the combination of these two regulatory mechanisms [14]. In the cases where the antitoxin binding is not efficient enough to abolish toxicity, cis-encoded mRNA elements sequestering the ribosome binding site (RBS) are also required for toxin repression [13].

We recently classified the type I toxins into two categories: membrane-associated type I toxins and cytosolic type I toxins [15]. The membrane-associated type I toxins generally contain less than 60 amino acids, are hydrophobic, and have a putative $\alpha$-helical transmembrane domain. For many of these type I toxins, the toxic activity is linked to membrane depolarization and/or permeabilization, followed by an intracellular ATP depletion [15]. The cytosolic type I toxins are RalR and SymE toxins that promote DNA or RNA cleavage, respectively [16,17].

In this review, we will focus on the membrane-associated type I toxins from either Gram-negative or Gram-positive species with a characterized mechanism of action. We describe the current state of the art on protein folding and membrane interactions of these bacterial toxins and we will attempt to establish a chronology of their toxic effects on the bacterial cell. As a new result, we will also investigate, by NMR, the structure of the sprG1-encoded membrane peptides that belongs to the sprG1/SprF1 type I TA system expressed in S. aureus and discuss the putative membrane interactions responsible to the lysis of competing bacteria and host cells.

\section{Overview of the Membrane-Associated Type I Toxins across the Bacterial Species}

The membrane-associated type I toxins have only been described in Proteobacteria and Firmicutes [14]. We have classified the membrane-associated type I toxins whose structure and/or mechanism of action have been deciphered (Table 1). These small hydrophobic peptides like phage holins [8] or cationic antimicrobial peptides [18] all display an $\alpha$-helical 
transmembrane domain but have a strong diversity in length and amino acid sequence. The $\alpha$-helical structure was experimentally validated for some of them such as TisB, IbsC, and LdrD in Escherichia coli [19-21], Fst in Enterococcus faecalis [22], SprA1 and SprG1 in S. aureus ([23] and in this study), and AapA1 in Helicobacter pylori [24] (Figure 1). For the other type I toxins, we could predict the $\alpha$-helical transmembrane domain using the TMPRED algorithm along with the orientation of the computed in silico model of $\alpha$-helix from the inside (I) to the outside $(\mathrm{O})$ of the bacterial membrane with a given probability ranging from ++ to in decreasing order (https:/ / embnet.vital-it.ch/software/TMPRED_form.html, accessed on 5 April 2021) (Table 1). Among the common features, the C-terminal part is mainly predicted to be localized in the cytosol, except for the ShoB, HokB, SprA1, and SprG1 toxins, and has positively charged residues, except for $\mathrm{IbsC}$, ShoB, and DinQ (Table 1). These positively charged residues were shown to be crucial for the binding/anchoring of peptides on lipid bilayers and may help interactions with the bacterial membrane that is mostly negatively charged [25]. The presence of cysteine residues in HokB, ShoB, AapA1, and SprA1 suggests a possible dimerization/oligomerization of these toxins, leading to pore formation. Sequence requirements for toxicity have been demonstrated by mutagenesis approaches for the Fst, IbsC, and AapA1 toxins [20,24,26]. These studies revealed that only a few residues are critical for toxicity, but the lack of sequence conservation within the type I toxins impedes the prediction of amino acids essential for toxicity by homology searches using bioinformatics tools [8]. Despite several common features, the membrane-associated type I toxins exert distinct mechanisms of action based on toxin ectopic overexpression. We can distinguish type I toxins whose overexpression induces bacterial membrane alterations as primary detected and surely toxic effects such as membrane depolarization and/or permeabilization, and the type I toxins whose overexpression induces morphological changes in bacteria as a primary detected effect prior to membrane perturbations.

Extracellular medium

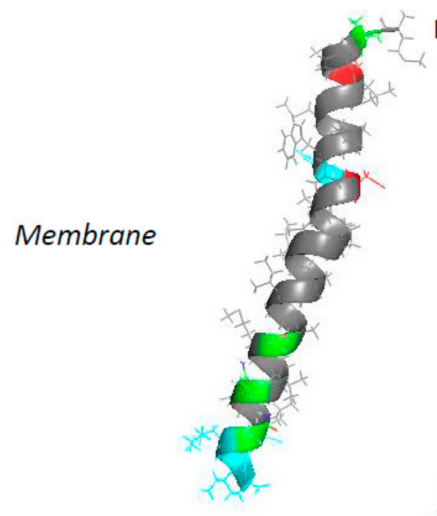

Cytosol

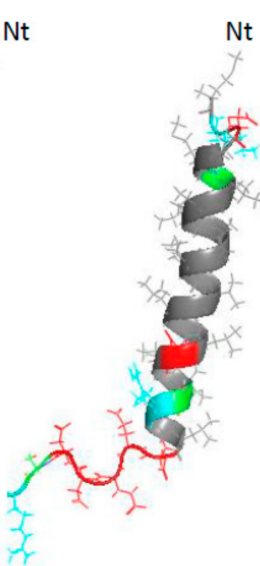

Fst (PDB id: 2KV5)

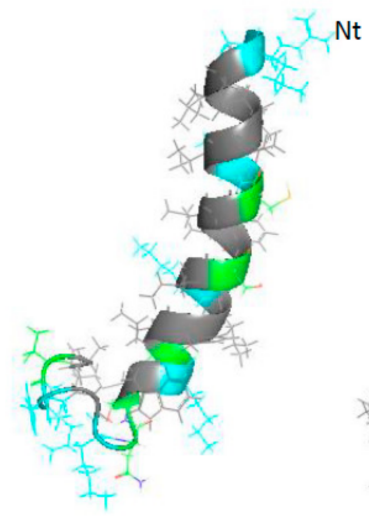

AapA1 (PDB id: 6GIG)

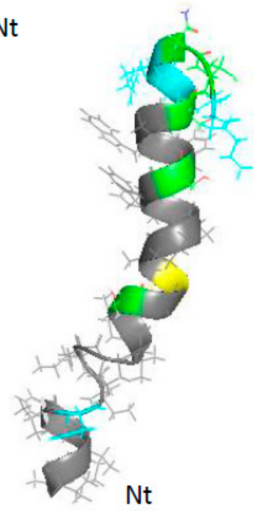

SprA1 (PDB id: 4B19)

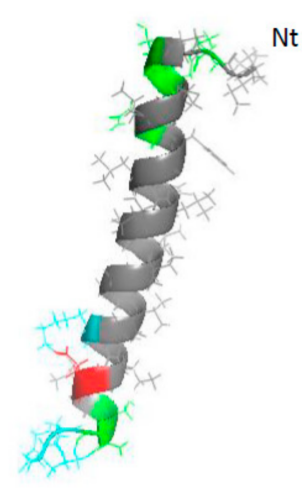

$\mathrm{SprG1}_{31}$ (PDB id: 7NS1)

Figure 1. Overview of the structurally determined membrane-associated type I toxins. Hydrophobic amino acids are represented in gray, polar amino acids in green, positively charged amino acids in blue, negatively charged amino acids in red, and cysteines in yellow. 
Table 1. Overview of membrane-associated type I toxins from toxin-antitoxin systems for which insights into their mechanism of action have been published. Predicted or experimentally determined (according to respective PDB file) $\alpha$-helix are highlighted in orange and $\beta$-sheet in yellow. When the structure has not been experimentally determined, $\alpha$-helix have been predicted with Jpred4 (http:/ / www.compbio.dundee.ac.uk/jpred/index.html, accessed on 5 April 2021) [27]. Transmembrane domains are delimited by lipid representation surrounding each sequence and have been predicted with TMPRED (https:/ / embnet.vital-it.ch/software/TMPRED_form.html, accessed on 5 April 2021). Boxes colored in blue correspond to the toxins inducing morphological changes as a primary detected effect, the green one for toxins inducing membrane perturbations as a primary detected effect and the grey one is for toxins with dual effects. Polar amino acids are shown in green, negatively charged amino acids in red and positively charged amino acids in blue. Cysteins are shown in orange. The charge and the hydrophobicity index (based on Kyte-Doolittle scale) have been calculated thanks to the $R$ package «Peptides» $[28,29]$. Unexpected results like low hydrophobicity or global negative charge have been written in red.

\begin{tabular}{|c|c|c|c|c|c|c|}
\hline $\begin{array}{l}\text { Bacteria } \\
\text { Species }\end{array}$ & Toxins & Size (aas) & Amino Acids Sequence with the $\alpha$-Helical Transmembrane Domain & $\begin{array}{c}\text { PDB ID and } \\
\text { Structural } \\
\text { Insights }\end{array}$ & Charge & $\begin{array}{l}\text { GRAVY } \\
\text { Index }\end{array}$ \\
\hline \multirow{8}{*}{ E. coli } & HokB & 49 & MKHNPLVVCLLIICITILTFTLLTRQTLYELRFRDGDKEVAALMACTSR $(0+)$ & \multirow[b]{3}{*}{$\begin{array}{l}\text { Molecular } \\
\text { modeling }\end{array}$} & 2.13 & 0.59 \\
\hline & TisB & 29 & MNLVDIAILILKLIVATCOLLDDVLKYLK $\quad(I+)$ & & 0.98 & 1.62 \\
\hline & LdrA & 35 & MTLAQFAMIFWHDLAAPILAGIITAAIVSW WRNRK $(I++)$ & & 2.22 & 0.76 \\
\hline & LdrD & 35 & MTEAELGMAFWHDLAAPVIAGILASMIVNWLINKRK $(I++)$ & PDB: 5LBJ & 1.22 & 0.69 \\
\hline & IbsC & 19 & MMMRLVIILIVTLLLISFSA & & 0.97 & 2.44 \\
\hline & ZorO & 29 & MDTLTQKLTVLIAVLELLVALLRLIDLLK $(I++)$ & & -0.02 & 1.40 \\
\hline & ShoB & 26 & MTDCRYLIKRVITITIAVTLOLILLFL $(O+)$ & & 2.94 & 1.59 \\
\hline & DinQ & 27 & MIDKAIIVKGALIA CLELIRFLLOLLN $(I++)$ & $\begin{array}{l}\text { Molecular } \\
\text { modeling }\end{array}$ & -0.02 & 1.79 \\
\hline E. faecalis & Fst & 33 & MKDIัMSLVIAPIFVGLVLEMI SRVLDEEDDSRK $(\mathrm{I}+)$ & PDB: 2KV5 & -3.02 & 0.42 \\
\hline B. subtilis & BsrG & 38 & MTVYESLMIMINFGGLILNTVLII FNIMMIVTSSQKKK $(\mathrm{I}++)$ & & 1.98 & 1.00 \\
\hline L. rhamnosus & Lpt & 29 & MNSFDKAOTIAPLLVGVFFLLLLKYAT:DNHK $(\mathrm{I}++)$ & $\begin{array}{l}\text { Molecular } \\
\text { modeling }\end{array}$ & 1.22 & 0.82 \\
\hline H. pylori & AapA1 & 30 & MATKHGKNSWKTัLYLKISFLGCKVVVLLKR $\quad(\mathrm{I}++)$ & $\begin{array}{c}\text { PDB: 6GIG + } \\
\text { Molecular } \\
\text { modeling } \\
\end{array}$ & 7.18 & 0.15 \\
\hline \multirow{3}{*}{ S. aureus } & SprA1 & 30 & MLIFVHIIAPVI ISGCAIAFFSYWLSRRNTK $(\mathrm{O}+)$ & $\begin{array}{l}\text { PDB: 4B19+ } \\
\text { Molecular } \\
\text { modeling }\end{array}$ & 3.18 & 1.00 \\
\hline & SprG1 $1_{31}$ & 31 & MITISTMLQF GLFLIALIGLVIKLIELSNKK (O-) & PDB: 7NS1 & 1.98 & 1.39 \\
\hline & SprG1 44 & 44 & MVALLKS LERRRLMITISTMLOFGLFLIALIGLVIKLIELSNKK $(0+)$ & $\begin{array}{l}\text { Molecular } \\
\text { modeling }\end{array}$ & 4.97 & 1.01 \\
\hline
\end{tabular}

\section{Membrane-Associated Type I Toxins Inducing Membrane Perturbations as a Primary Detected Effect}

\subsection{Membrane-Associated Type I Toxins Inducing Pore Formation}

The two well-characterized membrane-associated type I toxins HokB and TisB disrupt membrane integrity though pore formation in E. coli. The ectopic overexpression of these two pore-forming toxins causes membrane depolarization and generates dead cells socalled "ghost cells" with an unusual morphology characterized by cell material at the poles and a translucent cell center $[9,30]$.

The Hok type I toxin is expressed from the hok/Sok locus that is the first type I TA system discovered on the R1 plasmid in E. coli where it confers plasmid maintenance through PSK [9]. The hok/Sok locus codes for three genes: hok (for host killing), sok (for suppression of killing), and mok (for mediation of killing). The hok gene encodes a 52 amino acid membrane-associated peptide whose ectopic overexpression provokes loss of membrane potential and arrest of respiration, and kills bacteria within 30 min upon induction (Figure 2) [9]. The activation of hok translation in R1 plasmid-free cells is linked not only to the absence of the unstable Sok RNA antitoxin but also to the 3'-end processing and refolding of the hok mRNA, which increase its activity and stability [31]. In plasmid-carrying cells, 
the Sok RNA antitoxin binds to the mok-hok mRNA at the level of the Shine-Dalgarno (SD) sequence of mok encoding the Mok peptide, upstream of hok. The degradation of this RNA duplex by the RNAse III prevents translation of the hok mRNA, leading to cell growth [31]. Five hok/Sok homologues were discovered later in the E. coli chromosome, but many of them are non-functional due to mutations, insertions, or large rearrangements [10]. By singlecell approach, the Michiels group demonstrated that the GTPase ObgE promotes E. coli persistence through transcriptional activation of $h o k B$ expression, requiring the stringent response alarmone (p)ppGpp [32]. The GDP or ppGpp binding seems to be required for the GTPase ObgE to induce hokB transcription [33]. The deletion of hokB does not impact $E$. coli persistence, but the ectopic overexpression of hokB increases the number of persister cells in response to ofloxacin or tobramycin exposure [32]. The relationship between the mode of action of the 49 amino acid membrane-associated peptide HokB and E. coli persistence was elucidated in 2018 [34]. Using in vitro conductance measurements with synthetic or natural planar lipid bilayers, the authors showed that HokB targets the lipid bilayer and forms pores with an estimated diameter of 0.59-0.64 $\mathrm{nm}$ [34]. Changes in conductance using specific PEGylation demonstrated that HokB crosses the lipid bilayer with its positively charged $\mathrm{N}$-terminal domain extending in the cytoplasm, whereas the negatively charged Cterminal domain extends in the periplasm [34]. Thanks to a m-Cherry tag at the N-terminal domain, the authors showed by microscopy cluster formation of HokB peptides at the E. coli membrane, consequently to an in vivo pore formation. By blocking these HokB pores with PEG 1000 in vivo, the group elegantly proved that pore formation by HokB is directly linked to E. coli persistence and results in a decrease of the cellular energy ratio and the ATP efflux within $4 \mathrm{~h}$ upon induction. Moreover, the authors demonstrated in vitro that the membrane potential controls the size of HokB pores since, when the potential applied to the membrane is high, mature pores are formed and provoke both a membrane depolarization and an ATP efflux, leading to persistence in metabolically active cells (Figure 2). When the applied potential is low, intermediate pores can be formed. They induce ATP/ADP ratio drop, but no persister cells formation [34]. HokB overexpression triggers membrane depolarization and reactive oxygen species (ROS) formation within $1 \mathrm{~h}$ upon induction, leading to growth inhibition which could contribute to persister cells formation [35] (Figure 2). Recently, mechanisms that control the formation and the awakening of HokB-induced persister cells have been identified [36]. HokB contains three cysteine residues of which cysteines $\mathrm{C} 9$ and $\mathrm{C} 14$ are predicted to be part of a transmembrane $\alpha$-helix anchored to the membrane and cysteine C46 to be present in the periplasmic C-terminal domain (Table 1). Construction of cysteine-to-serine substitution mutants demonstrated that the periplasmic cysteine $\mathrm{C} 46$ is responsible for HokB dimerization by disulfide bridge formation as well as for HokB-induced membrane depolarization and persister cells formation [36]. The inter-peptide disulfide bridge formation between two periplasmic $\mathrm{C} 46$ residues is mediated by the periplasmic oxidoreductase DsbA. This enzyme is essential for HokB dimerization and stability and, consequently, for pore formation, membrane depolarization, ATP efflux, and persister cells formation [36]. A positive correlation between the concentration of HokB peptides and the dormancy duration in persister cells was evidenced by microfluidics and single-cell approaches. It suggests that pore disassembly may be involved in the awakening of HokB-induced persister cells. Upon awakening, the periplasmic oxidoreductase DsbC was shown to reduce the disulfide bridges and induce HokB monomerization, thus promoting DegQ-mediated degradation of HokB peptides. This pore destabilization leads to membrane repolarization and ATP production by the NADH-dehydrogenase complex I and to resume the growth of HokB-induced persister cells [36]. 


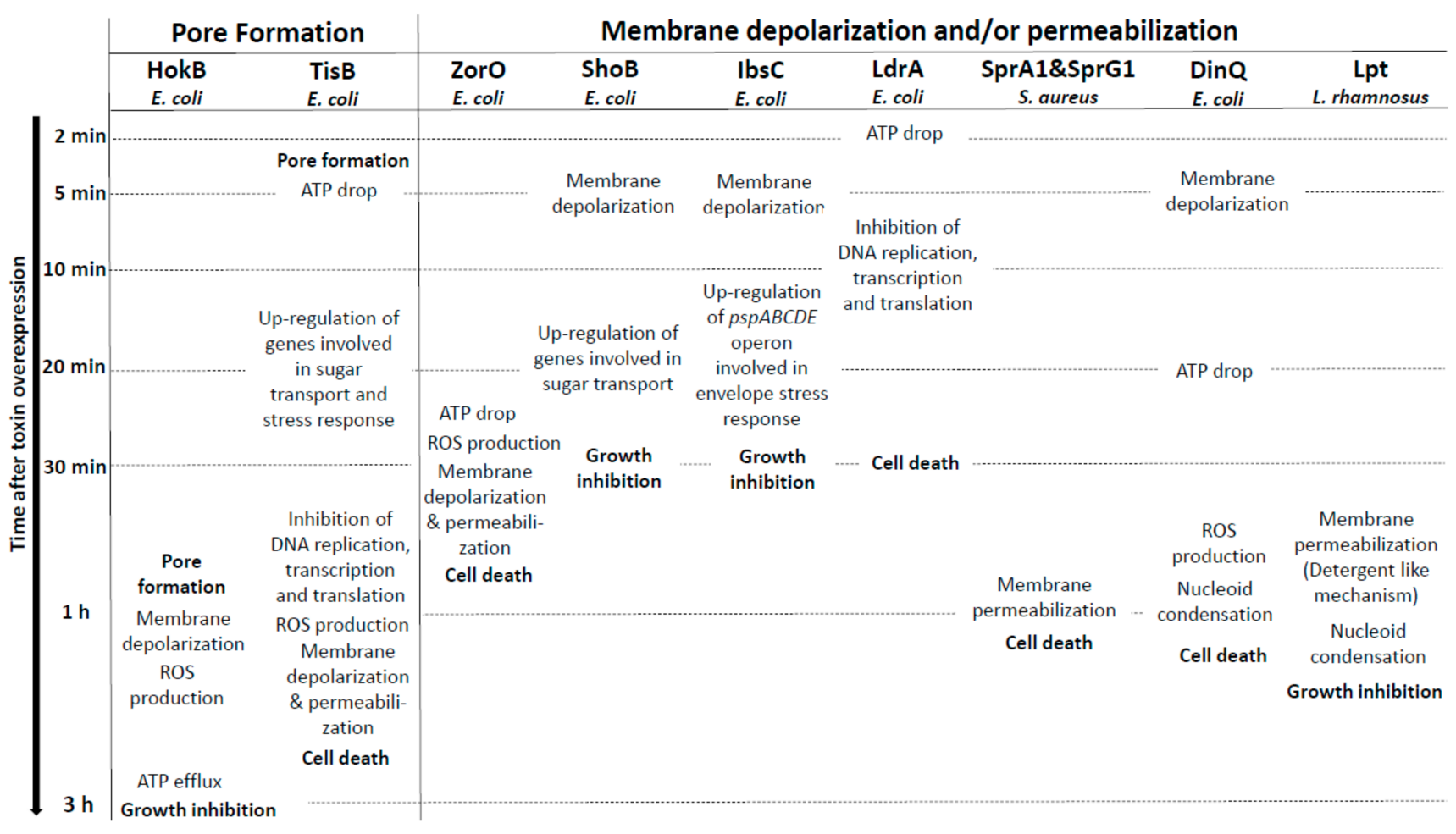

Figure 2. Overview of the membrane-associated type I toxins inducing membrane perturbations as primary detected effect. Only the effects of membrane-associated type I toxins after induction of their overexpression in bacteria have been shown in the figure.

The TisB type I toxin is another pore-forming peptide expressed in E. coli from the tisB/IstR-1 locus that was discovered by the first genome-wide searches for bacterial small RNAs [37,38]. The Wagner group demonstrated that tisB/IstR-1 is the first type I TA system involved in the SOS response [39]. The SOS response is initiated when the recombinase RecA senses DNA damage and activates cleavage of the global repressor LexA [40]. The tis $B$ (for toxicity induced by SOS) gene encodes a 29-amino-acid peptide located in the inner membrane of $E$. coli [30]. Its ectopic overexpression provokes membrane damages and a rapid drop in ATP levels that results to a drastic decrease in transcription, translation, and replication rates, leading to cell death within $1 \mathrm{~h}$ upon induction (Figure 2) [30,39]. Under normal growth conditions, the transcription of tisB is repressed by LexA. When SOS conditions are encountered, RecA-induced cleavage of LexA derepresses tis $B$ [39]. The high tisB mRNA levels out-titrate the IstR-1 (for inhibitor of SOS-induced toxicity by RNA) RNA antitoxin pool, despite its constitutive expression, and promotes cell growth arrest [39]. It was proposed that the IstR- 1 antitoxin prevents inadvertent toxicity that results from leaky tis $B$ transcription. IstR-1 RNA base-pairs with the standby site of the active +42 tis $B$ mRNA and promotes RNA duplex degradation by RNase III to an inactive +106 tis $B$ mRNA, thus preventing ribosome access and toxin translation [41]. The effects of TisB on the membrane integrity, decreasing intracellular ATP levels and all essential cellular processes [30], were associated to E.coli persistence in 2010. The Lewis group showed that ciprofloxacin, a DNA-damaging antibiotic targeting DNA gyrase and topoisomerase IV, increases persister levels via SOS-dependent induction of TisB [42]. A strain deleted for the tisB locus showed a 10-to-100-fold decrease of ciprofloxacin-tolerant persisters, whereas deletion of the ist $R-1$ locus resulted in a 10-to-100-fold increase [42]. Moreover, ectopic overexpression of TisB confers multidrug tolerance. The authors hypothesized that, in the presence of DNA-damaging antibiotics, the optimal strategy to survive is dual encompassing DNA repair activation and switching to a dormant state via the SOSinduced TisB expression [42]. The Wagner group demonstrated that the deletion of two regulatory RNA elements (i.e., Ist-R1 ... ) and the inhibitory $5^{\prime}$ UTR structure in the tisB 
mRNA [41] triggers stochastic TisB translation, leading to pore formations and superoxide production $[35,43]$. This results in a depolarized sub-population that turns into persister cells even in the absence of strong SOS induction by exposure to ciprofloxacin $[43,44]$. The deletion of the superoxide dismutases SodA and SodB impairs the stochastic TisBdependent persisters' formation and the recovery of persister cells after ciprofloxacin exposure [35]. In 2012, two studies investigated the structure of TisB and its interaction with model of bacterial membranes. The first study showed by in vitro conductance measurements and polymer-exclusion experiments that TisB forms narrow anion-selective pores in planar lipids bilayers as consequence of the net-positive charge of TisB [45]. The other study confirmed the amphiphilic $\alpha$-helical conformation of TisB by circular dichroism, oriented circular dichroism, and molecular dynamic (MD) simulations. The authors showed a spontaneous insertion of TisB in lipid bilayers with a stable transmembrane alignment where the four charged side-chains of D5, K12, D22, and K26 lie on a narrow strip along with the polar face of the helix, with an alternating pattern of positive and negative charges. They also postulated formation of a spontaneous assembly as antiparallel dimers stabilized by four intermolecular salt bridges and an intermolecular hydrogen-bond interaction between Q19 residues (Table 1) [19]. The polar interface of the TisB helix could mediate the passage of protons across the hydrophilic lipid bilayer. Fluorescence dequenching experiments confirmed that TisB can form narrow pores of an estimated diameter of $0.15 \mathrm{~nm}$ that are impermeable to intracellular water-soluble components, thus allowing cell survival $[19,45]$. The flows of protons and anions across TisB pores can dissipate the proton motive force (PMF), reduce the ATP production, and hijack the metabolism to a dormant state (Figure 2). Consequently, TisB leads to the shutdown of the major antibiotic targets and induces multidrug tolerance.

\subsection{Membrane-Associated Type I Toxins Inducing Membrane Depolarization and/or Permeabilization}

For some membrane-associated type I toxins, the ectopic overexpression rapidly induces membrane depolarization and/or permeabilization, but the mechanism of action has not been clearly demonstrated by biophysical approaches.

This is the case for the SprA1 (for Small pathogenicity island RNA) type I toxin (also named PepA1) of the sprA1/SprA1 AS TA system expressed in S. aureus and that displays homology with the Fst/Ldr family $[8,46,47]$. SprA1 is a 30 -amino acid peptide located in the membrane whose ectopic overexpression causes $S$. aureus cell death through membrane permeabilization within $1 \mathrm{~h}$ upon induction (Figure 2) [23]. The sprA1 mRNA expression is prevented in trans by the SprA1 $1_{\text {AS }}$ cis-RNA antitoxin that base-pairs with the internal RBS and thus inhibits the toxin translation [46]. Scanning electron microscopy (SEM) shows that synthetic SprA1 provokes the lysis of competing bacteria, such as S. aureus and E. coli, and of human erythrocytes [48]. Consequently, in contrast to Fst and AapA1 toxins [22,24], SprA1 has an antibacterial action when added to the extracellular medium, supporting the idea that its primary toxic effect flows from its interaction with the membrane. The 3D model of the structure of SprA1 performed by NMR supports this hypothesis. SprA1 folds into an extended amphipathic transmembrane $\alpha$-helix that is interrupted at the P10 proline residue and slightly bends at the C15 cysteine residue in the conserved PXXXGC motif of the Fst/Ldr family [23,49]. The N-terminus of SprA1 is unfolded and the positively charged C-terminus is folded (Table 1, Figure 1). In silico MD simulations show that, when inserted in a DPPC bilayer solvated by water molecules, the NMR SprA1 structure rapidly changes its conformation into an uninterrupted extended $\alpha$-helix (Figure 1) [23]. SprA1 also releases the cytoplasmic content of cells like the cationic antimicrobial peptide nisin, known to form pores leading to $S$. aureus cell death. The authors hypothesized that SprA1 could be a pore-forming toxin [48]. Moreover, the presence of the C15 at a flexible hinge in the $\alpha$-helix suggests a possible dimerization that could help to form pores as shown for HokB [34]. Future biophysical studies are needed to decipher the mechanisms of action responsible for the permeabilization of both prokaryotic and eukaryotic cell membranes. The expression of SprA1 is induced upon acidic or oxidative stress in response to a drastic decrease of 
SprA1 $1_{\mathrm{AS}}$ levels [23]. One hypothesis is that, after its internalization by phagocytes that triggers deleterious oxidative and acidic bursts, S. aureus would induce SprA1 expression to disrupt the phagolysosome and cell membranes to escape the immune cells, kill competing bacteria, and spread into the host.

Another example is the Lpt toxin, a 29-amino-acid peptide expressed from the type I TA system RNAI/RNAII identified in the plasmid DNA of Lactobacillus rhamnosus by its sequence homology with Fst (Table 1) [50]. Induction of Lpt expression in E. coli causes growth arrest, nucleoid condensation, and membrane permeabilization within $1 \mathrm{~h}$ upon induction (Figure 2). However, $3 \mathrm{~h}$ after induction, the E. coli growth resumes concomitantly with the recovery of nucleoid compaction and membrane damages, highlighting that the toxin overexpression leads to cell stasis instead of cell death [51]. Both morphological modifications and membrane perturbations effects have been observed at least $1 \mathrm{~h}$ after induction. However, surface visualization by AFM of Lpt-expressing E. coli cells evidence membrane patches linked to a disruption of the lipid bilayer. The authors suggest that Lpt acts through a detergent-like mechanism where the peptide, when added at high concentration, micellizes the lipid bilayer [51]. Despite these observations, it is not excluded that cell morphology changes induced by Lpt overexpression could be the primary triggers of its toxic effect. The membrane localization of Lpt was evidenced by the fusion of the red fluorescent protein $\mathrm{m}$-Cherry to the $\mathrm{C}$-terminus of the peptide. This fusion or the removal of the hydrophilic C-terminal region abolishes the toxicity of Lpt, supporting the importance of the $\mathrm{C}$-terminal domain for toxicity. Moreover, the substitution of a proline (P11) by a charged glutamic acid in the $\alpha$-helical transmembrane domain also suppresses the toxicity of Lpt, suggesting that the distortion of the $\alpha$-helix induced by P11 is essential for the interaction with the membrane and thus, for the toxicity, as this is the case for Fst [26]. Although Lpt, Fst, and SprA1 all share the conserved motif APXXXGXXX, where $X$ represents hydrophobic amino acids (Table 1) [23,52], it seems difficult to predict a similar mechanism of action for these three toxins. Indeed, the SprA1 homologue, SprA2 (also named PepA2), that displayed the conserved PXXXGC motif, does not lyse bacterial cells extracellularly but has a more hemolytic effect than SprA1 [13]. Lpt induces cell morphology changes and it is not excluded that this could be the primary trigger of its toxic effect. For this TA system, the molecular mechanisms involved in the regulation of Lpt expression by the RNA II antitoxin are currently unknown.

Five other type I toxins expressed by E. coli (namely ZorO, IbsC, ShoB, LdrA, and DinQ) rapidly cause membrane depolarization and/or permeabilization and/or intracellular ATP drop when overexpressed. The ZorO type I toxin was identified by bioinformatics with search parameters including tandemly duplicated, small, hydrophobic proteins by the Fozo group [8]. ZorO (for Z-protein often repeated) is a 29-amino-acid peptide (Table 1) whose expression is tightly repressed by a $5^{\prime}$-UTR secondary structure that sequesters the RBS of zorO mRNA and by the OrzO (for Overexpression reduces $\mathrm{Z}$ protein toxicity) RNA antitoxin that base pairs to the EAP (for Exposed After Processing) region located upstream of the RBS of zorO mRNA [11,53]. When overexpressed in E. coli, ZorO localizes at the inner membrane and induces membrane depolarization associated with a reduction of the intracellular ATP level and an increase of ROS production, leading to the membrane permeabilization and finally to cell death within 30 min (Figure 2) [8,54]. A mutagenesis analysis on ZorO demonstrated that only the five amino acids "ALLRL" spanning positions 20 to 24 are necessary for toxicity while the $13 \mathrm{~N}$-terminal amino acids are dispensable [54]. Conversely to full-length ZorO, the ALLRL peptide, when added to the extracellular medium, exhibits antimicrobial activity against the Gram-positive bacteria S. aureus and B. subtilis and against the fungus $C$. albicans through a mechanism of membrane permeabilization. However, it does not inhibit $E$. coli growth, suggesting that the outer membrane of Gram-negative bacteria prevents its binding to the inner membrane [54]. These observations indicate that accessibility to the inner membrane is essential for ZorO to exert its toxicity against $E$. coli.

The IbsC (for Induction brings stasis) and ShoB (for Short hydrophobic ORF) type I toxins from the $i b s C / \mathrm{SibC}$ and $s h o B / O h s C$ TA systems were discovered in $E$. coli by a 
bioinformatics analysis designed to identify new TA systems [55]. IbsC and ShoB are, respectively, 19- and 26-amino-acid peptides whose expression is prevented by SibC (for Short intergenic abundant sequence) and OhsC (for Oppression of hydrophobic ORF by sRNA) RNA antitoxins [56]. SibC interacts with the $i b s C$ mRNA through the TRD1 (for Target Recognition Domain) and TRD2 domains to repress IbsC toxicity [57]. IbsC and ShoB overexpressions induce membrane depolarization within 5 min upon induction followed by 20 min of incubation with dye (50\% and $98 \%$ of depolarized cells for $\mathrm{IbsC}$ and $\mathrm{ShoB}$, respectively), leading to a massive decrease of cell viability within $30 \mathrm{~min}$ upon induction (Figure 2) [56]. IbsC and $\mathrm{ShoB}$ are predicted to display a transmembrane domain. The formation of an $\alpha$-helix has been confirmed by CD experiment for $\mathrm{IbsC}$ (Table 1) [20]. A mutagenesis approach revealed that the IbsC sequence can be reduced to 15 amino acids with a minimum of 10 hydrophobic residues to retain toxicity and probably keep the helix translocation across the inner membrane. This minimal sequence requires the C-terminal residues and the hydrophobic residues near the center of $\mathrm{IbsC}$ to keep toxicity (residues 6 to 19), suggesting that these residues are probably involved in the promotion of a proper transmembrane 3D conformation and/or protein-protein interactions. On the contrary, the $\mathrm{N}$-terminal residues deletion did not impact the toxicity of IbsC, except for V5 [20]. Whole genome expression analyses carried $20 \mathrm{~min}$ after IbsC, ShoB, LdrD, or TisB overexpressions showed the induction of a common set of genes encoding membrane proteins and/or proteins involved in sugar transport and in stress response, as the soxS mRNA encoding a regulator of the superoxide stress response [56]. These observations are not surprising as these type I toxins are localized on membrane and induce cell toxicity. The individual overexpression of each toxin also induces the expression of specific genes. Interestingly, IbsC overexpression specifically increases the expression of the $p s p A B C D E$ operon where PspA protein, known to be induced by pore-forming proteins [58], can interact with phospholipids to block the passage of protons across the damaged membrane [56]. Moreover, ShoB overexpression up-regulates the expression of genes involved in sugar transport. These gene regulations could be linked to a direct effect of the toxins on membrane or metabolism or to a secondary consequence of membrane depolarization [56,59].

The 35-amino acid LdrA toxin, which belongs to the Ldr (for Long direct repeat) family of type I TA systems, rapidly induces intracellular ATP drop within 2 min upon induction. This results in a simultaneous inhibition of DNA replication, transcription, and translation within $10 \mathrm{~min}$ upon induction and, finally, to cell growth arrest within $30 \mathrm{~min}$ upon induction (Figure 2) [60]. This timing strongly suggests a direct effect of LdrA on the integrity of the membrane. LdrA forms an $\alpha$-helix confirmed by circular dichroism and is predicted by MD simulations to cross the inner membrane of E. coli with positively charged C-terminal domain located in the cytosol (Table 1) [60]. The toxicity of LdrA is abolished when a His-tag is added at the N-terminal domain, suggesting the importance of this domain for the anchoring in the inner membrane, leading to the inhibition of ATP synthesis [60]. It can be noted that LdrA is the one of few type I toxins for which the extracellular N-terminal part has been demonstrated to be essential for its toxicity. As for Lpt, the molecular mechanisms involved in the regulation of LdrA expression by its antitoxin remain to be deciphered.

The DinQ type I toxin from the $\operatorname{din} Q /$ AgrB TA system is a 27 -amino-acid peptide identified in E. coli as a new gene of the LexA regulon involved in the SOS response to DNA damaging agents like UV $[37,57,61]$. DinQ is located within the inner membrane of $E$. coli and its ectopic overexpression induces membrane depolarization within 5 min upon induction followed by $20 \mathrm{~min}$ of incubation with the dye, leading to cell death and a high UV sensitivity counteracted by the AgrB RNA antitoxin [62]. AgrB base pairs to the $\operatorname{din} Q$ translationally active +44 transcript, resulting in the sequestration of the SD sequence, the cleavage of the duplex by RNase III, and, consequently, preventing ribosome access and toxin translation [63]. These observations have been supported in the agrB mutant, whose DinQ overexpression displays not only an intracellular ATP drop before and after UV ex- 
posure, an increase of UV susceptibility, but also an impairment of conjugal recombination and an increase of cells with a compacted nucleoid [62]. The authors suggest that DinQ affects the transformation of the nucleoid morphology in response to UV damage and that it could regulate at the inner membrane the DNA repair of hyperstructures associated with homologous recombination, as an additional effect of membrane perturbation [62]. As demonstrated for HokB, TisB, and ZorO, DinQ overexpression also provokes ROS formation within $1 \mathrm{~h}$ upon induction, which seems to be a key event for these toxins promoting cell death and which may be linked to pore formation (Figure 2) [35]. Structure predictions revealed that DinQ can form a transmembrane $\alpha$-helix where the two positively charged lysine residues (K4 and K9) are close to the phospholipid head groups and where E17, R20, and Q24 residues may form a polar patch that can interact with other membrane proteins (Table 1) [62]. As a conclusion, the primary toxic effect of DinQ is controversial: some clues suggest that DinQ is a membrane-disrupting toxin [58], while others suggest that DinQ is involved in nucleoid compaction [64].

Finally, we described here eight toxins whose overexpression leads to a membrane perturbation as a primary detected effect. For two of them, the cause of this membrane perturbation is well investigated and due to pore formation. We also presented two other toxins, Lpt and DinQ, which are suspected to target the membrane as a first toxic effect but whose overexpression also leads to morphological changes detected at the same time. More information about the timing of the effect of toxins overexpression is needed to conclude. To note, most of these toxins are found in E. coli genomes, which could be a bias because E. coli has been more studied than other bacteria.

\section{Membrane-Associated Type I Toxins Inducing Cell Morphology Changes as a Primary Detected Effect}

Some membrane-associated type I toxins affect bacterial inner membranes, but cell morphology changes are induced as primary detected effects prior to membrane damages. This class of type I toxins is represented by Fst, BsrG, AapA1, and LdrD toxins and probably by Lpt and/or DinQ toxins as discussed before.

The Fst (for faecalis plasmid stabilizing toxin) type I toxin is a 33-amino-acid peptide that belongs to the RNAI/RNAII PSK TA system, expressed from the par locus of the Enterococcus faecalis plasmid pAD1 [65]. The Weaver group demonstrated that, in E. faecalis and in the presence of the pAD1 plasmid, the interaction between RNAI, the messenger RNA encoding Fst, and the antitoxin RNAII is initiated at the loop of the intrinsic terminators and that it spreads to the DRa (for DNA direct repeats) and DRb sequences located at the $5^{\prime}$ end of both RNAs. This results in a sequestration of the GUG initiation codon of RNAI and subsequently to the inhibition of Fst translation $[66,67]$. The group also showed that RNAI SD sequence is sequestered within an intramolecular stem-loop and that translation repression is maintained until interaction with RNAII [68,69]. These studies also demonstrated that, upon pAD1 plasmid loss, RNAII, in complex with RNAI, is degraded by RNases and that Fst is produced from RNAI, resulting in cell death. Indeed, ectopic overexpression of Fst rapidly provokes a chromosome segregation defect evidenced by nucleoid condensation and misplaced septa, resulting in daughter cells with little or without DNA within 15 min after induction in E. faecalis (Figure 3) [70]. These cell division abnormalities precede the simultaneous inhibition of DNA replication, transcription, and translation, membrane permeabilization, and thus cell growth nearly 45 min after Fst induction, highlighting that morphological changes are the primary detected effects related to the toxicity of the toxin (Figure 3) [71]. Moreover, Fst overexpression did not lead to the formation of "ghost" cells or leakage of cellular content as for HokB and TisB toxins $[9,30,71]$, confirming that Fst is not a pore-forming toxin. Synthetic Fst has no effect on bacteria, fungal cells, or erythrocytes when added to the extracellular medium [22,71], indicating that Fst is localized within the membrane to facilitate interactions with a specific membrane-bound intracellular target or is intracellularly modified rather than being directed against the membrane itself as observed with antimicrobial peptides. Interestingly, microarray analysis showed that Fst overexpression increases the expression of several 
membrane transporters $1 \mathrm{~h}$ after induction. This expression is detrimental for the bacteria potentially by depleting the pool of intracellular ATP and/or by perturbing the membrane integrity secondary to defects on nucleoid structure, chromosome segregation, and cell division (Figure 3) [72]. CD, NMR, and MD simulation experiments demonstrated that Fst forms an $\alpha$-helical transmembrane structure between amino acids 4 and 26 with a slight bend at the G15 and a disordered charged C-terminal domain (Table 1). The presence of negatively charged residues (D26 to D30) at the C-terminal domain suggests that Fst binds to the cell membrane with the C-terminus pointing into the cytosol since the outer side of Gram-positive membranes is negatively charged (Figure 1) [22]. The authors hypothesized that Fst anchoring at the membrane facilitates binding with membrane-bound target through the C-terminal domain, which would become structured after binding [22]. However, mutagenesis analysis demonstrated that the Fst C-terminal domain is dispensable for the toxin toxicity, although its deletion seems to reduce toxicity [49]. Conversely, the hydrophobic domain, notably the P11 and the G15 residues present in the conserved motif APXXXGXXX, and the two charged amino acids K2 and D3 at the N-terminus, are essential for the toxicity of Fst [26].

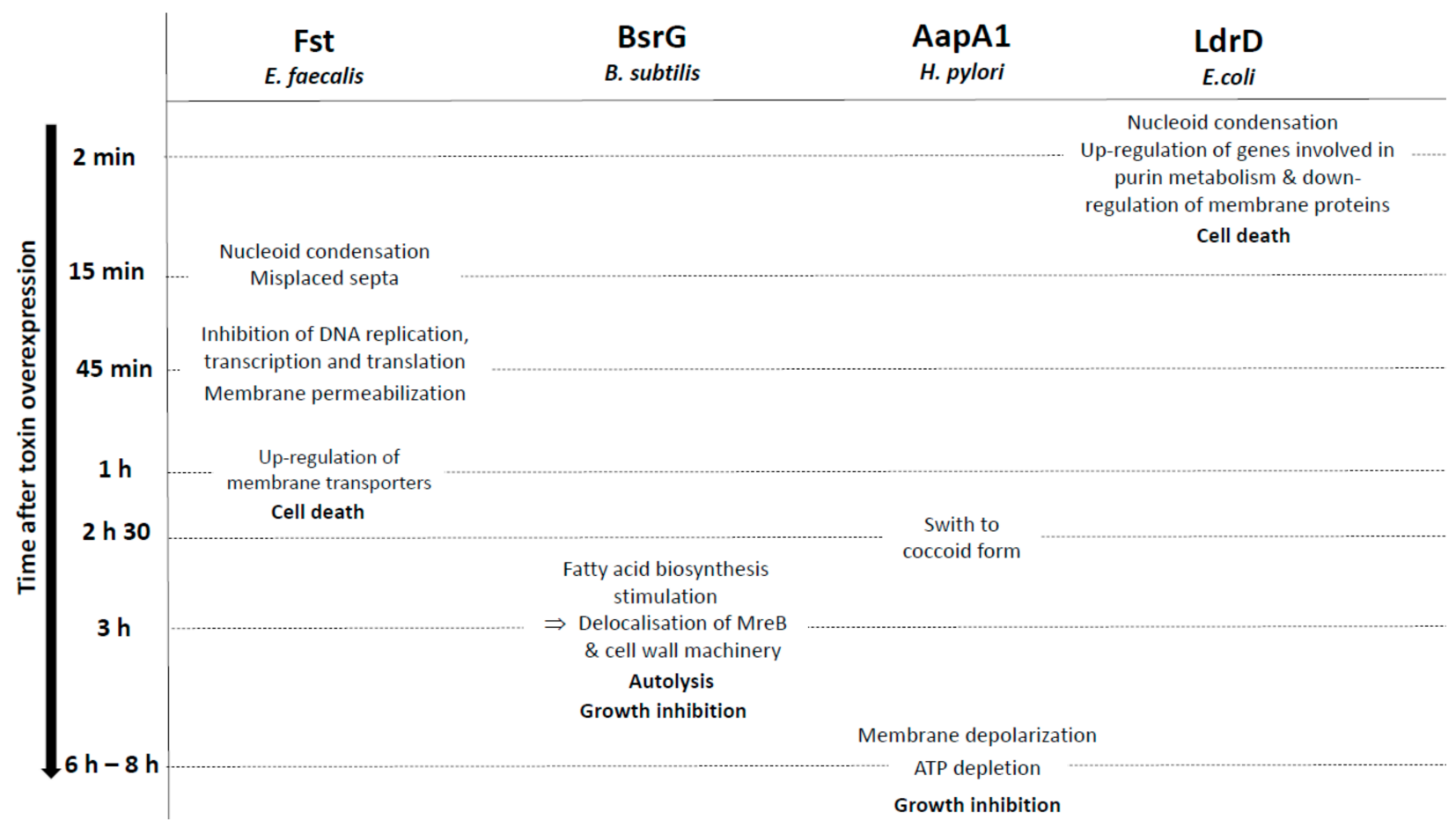

Figure 3. Overview of the membrane-associated type I toxins inducing cell morphology changes as a primary detected effect. Only the effects of membrane-associated type I toxins after induction of their overexpression in bacteria have been shown in the figure.

The BsrG type I toxin is a component of the temperature-dependent $b s r G / S R 4$ TA system located on the SP $\beta$ prophage region of the Bacillus subtilis chromosome [73]. The bsrG mRNA encodes a 38-amino-acid hydrophobic peptide whose ectopic overexpression causes cell lysis on agar plates. This toxicity is reversed by the bifunctional SR4 RNA antitoxin that interacts with $b s r G$ mRNA via its overlapping 3'-end, leading to the RNase III-mediated degradation of the $b s r G / S R 4$ duplex and to the $b s r G$ mRNA translation inhibition by sequestering the Shine-Dalgarno (SD) sequence [73,74]. To analyze the mechanism of action of BsrG toxin, the $b s r G$ gene is integrated into the aprE locus of the B. subtilis chromosome under the control of an IPTG-inducible promoter. In this condition, the BsrG expression causes a slight growth inhibition of B. subtilis $3 \mathrm{~h}$ after IPTG induction (Figure 3) [75]. Although the BsrG toxin is associated with the cell membrane, its IPTG-inducible expression induces neither membrane permeabilization and depolarization, nor alteration of 
membrane fluidity and intracellular ATP level [75]. However, $b s r G$ induction provokes morphological abnormalities visualized by 3D-structured illumination microscopy such as reduced cell size, irregular shape, distorted cell division planes, membrane invaginations, and irregular septa [75]. BsrG also induces nucleoid condensation without alterations in chromosome segregation and replication and promotes a global inhibition of transcription and translation as a secondary consequence of its toxicity. After a detailed analysis of the different effects of BsrG overexpression, the authors concluded that BsrG stimulates fatty acids biosynthesis, causing invaginations of the cytoplasmic membrane, leading to the delocalization of the cytoskeletal protein MreB and the accompanied cell wall synthesis machinery. This triggers cell lysis, which is dependent of LytC and LytD autolysins [75]. However, the direct cellular target of BsrG is not the cell wall synthesis machinery and remains to be identified [76]. From a structural point of view, addition of the monomeric superfolder GFP to the C-terminus of BsrG removes the toxicity, suggesting that the cationic and polar C-terminal domain predicted to be located inside the cell (Table 1) is essential for the interaction of BsrG with an intracellular target [75].

The H. pylori AapA1 type I toxin is a 30-amino-acid peptide from the aapA1/IsoA1 TA system initially discovered by global transcriptome analysis in H. pylori 26695 strain [77]. Structural rearrangements of the aapA1 mRNA leads to a duplex formation with the cisencoded IsoA1 RNA antitoxin [78]. This interaction promotes the translation inhibition of the aapA1 mRNA and its degradation by RNase III, thus preventing toxin synthesis under normal growth conditions [78]. The ectopic overexpression of AapA1 leads to a growth arrest characterized by a rapid morphological transformation of $H$. pylori from spiral-shaped bacteria to round coccoid cells $[78,79]$. This transformation occurs as early as $2.5 \mathrm{~h}$ after toxin induction that corresponds to the division time of H. pylori. AapA1 is exclusively located to the inner membrane [24,79]. The intracellular ATP level and the membrane potential are weakly affected $6 \mathrm{~h}$ and $8 \mathrm{~h}$ after AapA1 induction, whereas most cells are transformed into viable coccoids (Figure 3) [79]. Experiments using in vitro membrane models, Plasmon waveguide resonance, MD simulations, and Cryo-EM demonstrated that the interaction between AapA1 and cell membrane induces a lipid reorganization and a thinning of the bilayer lipids without severe membrane disruption [24]. The structural analysis performed using NMR shows that the AapA1 toxin folds into three functional domains with an amphipathic $\alpha$-helical transmembrane segment spanning from S9 to L28, flanked by two positively charged domains that appear to be unfolded (Table 1). The first eight amino acid residues are not required for toxicity, in contrast to the two positively charged residues, K29 and R30, at the C-terminus [24]. The addition of a SPA tag sequence at the C-terminus also suppresses the AapA1 toxicity. The C-terminal part of AapA1 is localized in the cytosol, suggesting that the K29 and R30 residues allow the binding with an intracellular target, in addition to the membrane perturbations, to interfere with cell elongation and division, leading to the formation of viable coccoids [24,79]. Coccoids are induced by oxidative stress, probably through an increase of AapA1 expression consecutive to a drop of IsoA1 RNA level [79]. AapA1 represents an essential effector of the morphological conversion of $H$. pylori from spirals to coccoids observed in human gastric biopsies and compared to persister cells. However, the deletion of the five homologues of AapA toxins in $H$. pylori has no impact on the persister cells formation after oxidative stress exposure [79].

The LdrD toxin is part of the Fst/Ldr family of type I toxins and composed of 35 amino

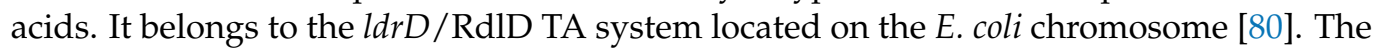
RdID (for Regulator detected in LDR) RNA antitoxin inhibits $l d r D$ mRNA translation, but the molecular mechanism of regulation is currently unknown. The ectopic overexpression of LdrD causes a rapid growth inhibition, loss of cell viability, and nucleoid condensation within 2 min upon induction (Figure 3) [80]. Due to the celerity of this morphological modification, the authors indicated that it is unlikely that the nucleoid condensation is linked to the accumulation of LdrD on the chromosome. The authors hypothesized that LdrD interacts with a specific cellular target important for maintaining the integrity of 
the nucleoid structure and the cell growth [80]. Microarray analysis showed that LdrD induction up-regulates the expression of genes involved in the purine metabolism and decreases the expression of proteins located in the membrane (Figure 3) [80]. It would be interesting to investigate the effect of the LdrD induction on the membrane permeabilization, the membrane depolarization, and the intracellular ATP level as performed for the BsrG and AapA1 type I toxins and for its homologue LdrA (57\% identity and $74 \%$ homology with $\mathrm{LdrD}$ ) to decipher the exact mechanism responsible for LdrD toxicity. NMR and CD assays showed that LdrD possesses an $\alpha$-helical transmembrane domain and binds to phosphocholine micelles without changing their size (Figure 1) [21; PDB id: 5LBJ]. Interestingly, LdrD exhibits two conserved cationic amino acids at its C-terminal domain, which are also found for LdrD, AapA1, Fst, BsrG, and SprG1 31 and SprG1 44 toxins. Notably, they are essential for the toxicity of AapA1 toxin also inducing morphological changes as a primary observable effect (Table 1) [24]. Mutagenesis analysis could be performed to identify the amino acids that confer the toxicity of LdrD towards E. coli.

\section{Protein Folding of the S. aureus sprG1-Encoded Type I Toxins}

We will present here original results concerning the first solution structure of the Staphylococcus aureus SprG1-encoded toxin peptide, determined by NMR. The SprG1encoded type I toxins belong to the sprG1/SprF1 TA system located within a pathogenicity island (PI) in S. aureus and identified by homology with the B. subtilis $\operatorname{txp} A /$ RatA type I TA system [8,81]. The $\operatorname{spr}$ G1 mRNA encodes two membrane peptides from a single internal reading frame: a long (44 amino acids, SprG1 $_{44}$ also named PepG1 $1_{44}$ ) and a short version ( 31 amino acids, SprG1 31 also named PepG1 31 ). The SprG1 44 peptide has 13 extra amino acids in the $\mathrm{N}$-terminus compared to $\mathrm{SprG}_{31}$ (Table 1). Ectopic overexpression of both SprG1-encoded peptides causes $S$. aureus cell death accompanied by disruption of membrane integrity within $1 \mathrm{~h}$ upon induction (Figure 2) [81]. The dual-function RNA antitoxin SprF1 promotes sprG1 mRNA degradation and prevents sprG1 mRNA translation by interacting in cis with its overlapping $3^{\prime}$-end [81]. Moreover, thanks to a purine-rich sequence located at its $5^{\prime}$-end, SprF1 also interacts with a subset of polysomes and ribosomes that could promote translation attenuation and persister cell formation [82]. The extracellular addition of chemically-synthesized peptides SprG1 44 and $\mathrm{SprG1}_{31}$ or of membrane extracts prepared from S. aureus cells overexpressing SprG1-encoded peptides trigger the lysis of both competing bacteria (Gram-negative and positive bacteria) and human erythrocytes [81]. To better understand the mechanism of action of the SprG1encoded peptides responsible for membrane permeabilization, we decided to solve their structure by NMR (Section S1, S2) and focused on the short SprG1 $1_{31}$ peptide (Figure 1). Chemically-synthesized SprG1 31 peptide is hydrophobic and thus not soluble in water. It dissolves upon addition of deuterated isopropanol. The addition of $50 \% \mathrm{v} / \mathrm{v} d 8$-isopropanol avoids the presence of undissolved peptide in the NMR tube and yields acceptable NMR resonances line broadenings. In such conditions, $\mathrm{SprG1}_{31}$ peptide adopts a single wellfolded conformation based on the TOCSY and NOESY spectra (Figure 4, PDB id: 7NS1). The 3D structure using NMR restraints displays an almost perfect $\alpha$-helix about $39 \AA$ long, ranging from I4 to S28. Most hydrophilic residues are at the $\mathrm{N}$ - and C-termini. The three N-terminal MIT residues and the three hydrophilic C-terminal NKK residues are unstructured, with enhanced flexibility for the C-terminus. Albeit not stacked, the two phenylalanine residues (F10 and F13) in the first half of the peptide are about $7 \AA$ from each other. They also share the same strongly hydrophobic side with L14, L17, I18, L20, and V21 (Figure S1). The NMR spectra recorded in the same conditions on the SprG1 44 peptide disclose large resonances especially in the $\mathrm{N}$-terminal region, indicating that this part of the peptide is not well structured and/or very flexible (Figure S2). Despite a poorer resolution, a good superposition is observed for the amino acids corresponding to the medium part and the C-terminus part of $\mathrm{SprG1}_{31}$ peptide (Figure S2). From the similarity of chemical shift and connectivities, we can conclude that the helical structure ranging from L8 to S28 in the SprG1 31 peptide is retained in SprG1 44 (i.e., from L21 to S41) (Table 1). In 
particular, the well-defined part of the $\alpha$-helix comprising the two phenylalanine residues is conserved. On the opposite, the cross-peaks of the amino acids I15-M20 corresponding to SprG1 $_{31}$ I2-M7 are shifted and/or broadened (sometimes broadened out to baseline), and many connections are lost. This indicates that the extra $\mathrm{N}$-terminal amino acids in $\mathrm{SprG1}_{44}$ peptide destabilizes the region corresponding to the N-terminus of the SprG1 31 peptide.

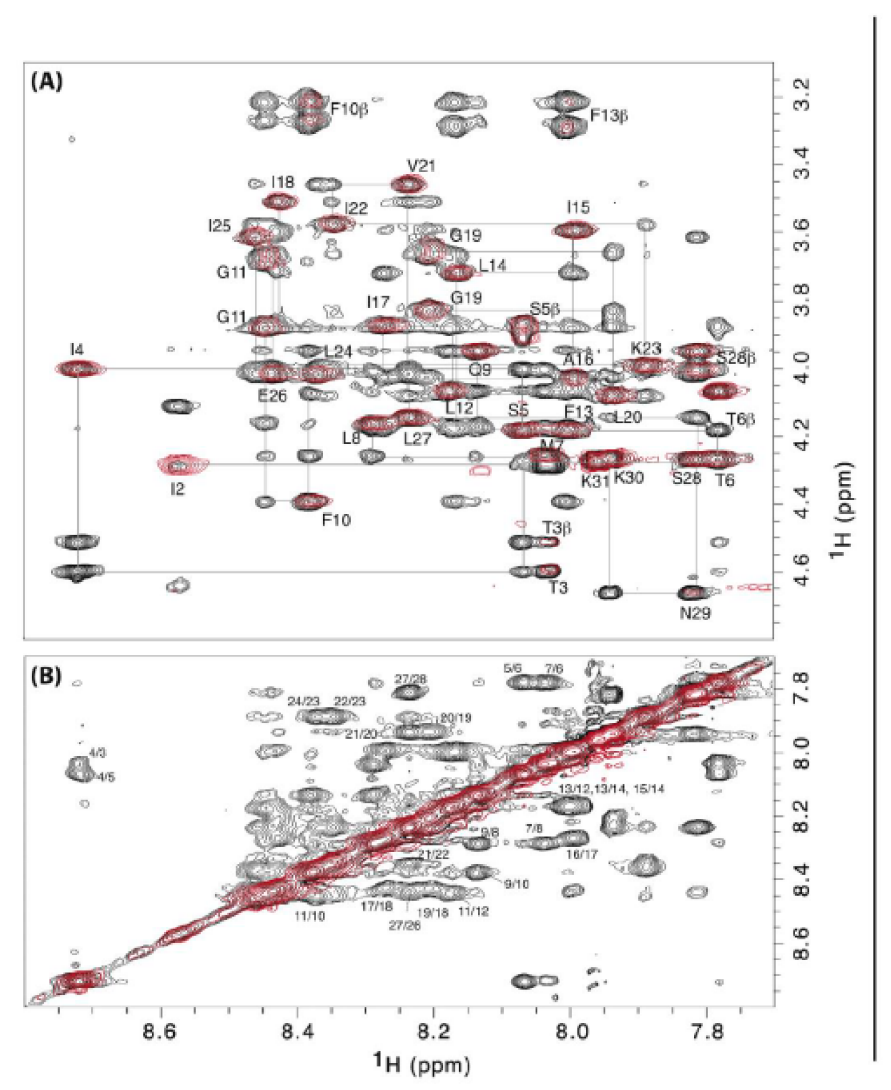

(C)

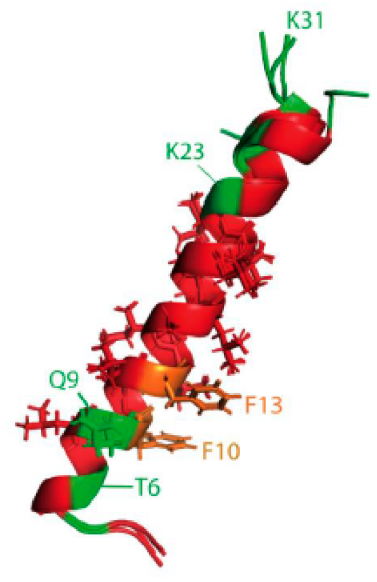

(D)

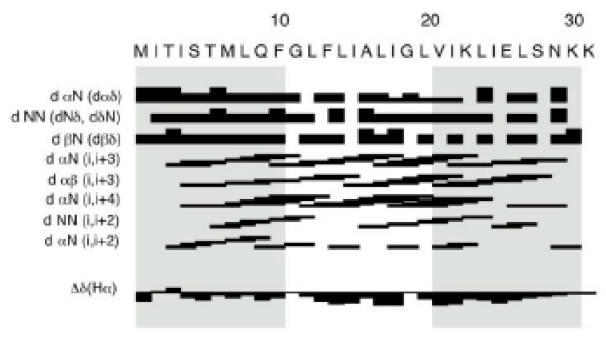

Figure 4. New SprG1 ${ }_{31}$ NMR 3D model of structure (PDB 7NS1). (A,B) Superposition of the $300 \mathrm{~ms}{ }^{1} \mathrm{H}-{ }^{1} \mathrm{H}$ NOESY spectrum (black) and the $80 \mathrm{~ms}^{1} \mathrm{H}^{-1} \mathrm{H}$ TOCSY spectra (red), both recorded at $303 \mathrm{~K}$ and $\mathrm{pH} 4.5$, showing the $\mathrm{NH}-\mathrm{H} \alpha$ (panel A) and NH-NH (panel B) connectivities. (C) Superposition of the five best structures of lower energies and Molprobity scores: hydrophilic amino acids are in green, hydrophobic in red and phenylalanines in orange. (D) Distance restraints chart.

In our experimental conditions, there is no evidence that $\mathrm{SprG}_{31}$ peptide undergoes conformational exchange or multimerizes. However, it is small and dimers, if totally symmetrical, would be undetectable by our NMR experiments. SprG1 $1_{31}$ and SprG1 $1_{44}$ peptides are known to accumulate at the $S$. aureus membrane and to be able to lyse competing bacteria and host cells [81]. The last half of the extra $\mathrm{N}$-terminal sequence of SprG1 $_{44}$ peptide is mainly hydrophilic and cationic (with a KSLERRR tract), explaining its higher cytolytic effect than $\mathrm{SprG1}_{31}$ against human erythrocytes [74]. Although we have no evidence for this, it is possible that the extra N-terminal amino acids of the "long" peptide display a signal sequence that may improve secretion efficiency. SprG1 44 may also interact with SprG1 31 and drags its shorter version like a cargo by intermolecular phenylalanine interactions to reach the bacterial or host cell membranes. Their hydrophobicity makes both peptides suitable for insertion in the bacterial and host cell membranes, in line with the experimentally observed lysis. In such a situation, the two phenylalanine of one monomer may each interact with one of the two phenylalanine of another monomer (from $\mathrm{SprG1}_{31}$ or $\mathrm{SprG1}_{44}$ peptide), thus helping to form a small pore in the membrane [83]. This mechanism, as well as possible transient interactions between both peptide during blood cell travel, are worth further investigations. Although SprG1 ${ }_{31}$ and SprG1 $_{44}$ peptides could also damage bacterial membranes and erythrocytes through a detergent-like effect, or by 
interference with membrane-associated functions, we cannot exclude a role of these toxins in morphological changes as nucleoid condensation.

\section{Concluding Remarks and Future Perspectives}

In this review, we present an overview of data on structure and membrane interactions of toxins that belong to type I TA systems. The common features of the membraneassociated type I toxins, a small size less than 60 amino acids, an important hydrophobic character, a putative $\alpha$-helical transmembrane domain, and the presence of cationic residues generally localized at the C-terminal domain, allow them to directly interact with bacterial membranes that are mostly negatively charged. In most cases, the membrane-associated type I toxins display their toxicity by interfering with membrane integrity through depolarization and/or permeabilization associated with an intracellular ATP drop. Only two type I toxins, HokB and TisB, have been experimentally demonstrated as pore-forming peptides. For HokB, the pore formation is directly linked to persister cells formation, in contrast to TisB. For the other toxins acting on membrane as a primary detected effect, the mode of action remains to be determined by a global biophysical approach. If they do not form pores, the mode of action of these type I toxins may follow the model of membrane disruption via the "carpet" mechanism in which peptides bind to the surface of the membrane and provoke a detergent-like effect as shown for antimicrobial peptides [84]. As exceptions, four type I toxins (Fst, BsrG, AapA1, and LdrD) display their toxicity by inducing morphological changes as primary detected effect prior to membrane disruption. This suggests that these toxins may exert their toxic effect indirectly or in conjunction with other partners. Some peptides have been described as regulating degradation of membrane proteins, stabilizing P-type ATPase transporters, and modulating the activity of two-component systems [85]. The anchoring of these peptides to the membrane could facilitate interactions with targets. When comparing the sequences and structures of membrane-associated type I toxins, it is difficult to see a common mechanism of action. As an example, LdrA and LdrD toxins display a different mechanism of action despite $74 \%$ sequence homology (Figures 2 and 3) [80]. Moreover, many studies reporting type I toxin actions were based upon episomal overproduction, which is an inadequate model where the toxin concentration is not controlled and generally much higher than in reality; it could induce off-target effects that would not appear in natural conditions. It can be also noted that, in most cases, the effect of the membrane-associated type I toxins on the bacterial morphology or on the membrane integrity is usually left unexplored, as only one of these effects is studied. Like DinQ or Lpt toxins, both changes can be observed after toxin overproduction and it is tempting to speculate that some toxins may act through both mechanisms to induce growth stasis or cell death. We aimed here at giving a chronology of the effects induced by the overproduction of toxins in order to highlight the primary effects on bacterial cells and to get insights to compare the associated mechanisms of action. Unfortunately, some studies only focused on the consequences of the overexpression at a specific time after induction and did not provide kinetic data. The information about these toxins is thus incomplete. It is also important that some experiments required an extra incubation time after sampling, like for membrane depolarization measurements, which gives a bias of the "time after induction" indicated in Figures 2 and 3. New hypotheses regarding the biological functions of the membrane-associated type I toxins will arise from a better understanding of their mechanisms of action and the identification of their molecular targets. Remarkably, in the case of type $\mathrm{V}$ ghoT/GhoS TA locus, the GhoT toxin is predicted to be a small membrane protein (57 amino acids) that alters membrane integrity, leading to a drop in PMF and ATP levels, thereby promoting E. coli persistence [86].

The membrane-associated type I toxins can be considered as lead compounds for the design of new antimicrobial drugs. Synthetic SprG1 $31, S p r G 1_{44}$, and SprA1 have a bactericidal action on $S$. aureus, E. coli, or P. aeruginosa when added in the extracellular medium [48,81]. Specific chemical modifications of SprA1 toxin dramatically increase its antibacterial potential and its stability in human serum with limited resistance while 
considerably reducing its human cell toxicity. This brings the proof of concept that toxins can be transformed into potent antibiotics [87]. Moreover, the peptide ALLRL from the ZorO toxin displays antimicrobial effects against the Gram-positive bacteria S. aureus and B. subtilis and the fungus C. albicans [54]. The DinQ toxin is another promising candidate for the development of anti-cell-envelope antibiotics, notably targeting E. coli infections [88]. These strategies could be applied to other type I toxins, notably for the design of new antibiotics, thus providing alternatives to eradicate resistant bacteria as well as persister cells.

Supplementary Materials: The following are available online at https://www.mdpi.com/article/ 10.3390/toxins13070490/s1, Section S1: NMR Sample Preparation and Experiments, Section S2. Structure Determination, Figure S1: SprG131 peptide: hydrophobicity surface, Figure S2: (A): Alignment of SprG131 and SprG144 sequences. SprG131 $\alpha$ helix is highlighted in orange. The resonances of the SprG144 underlined residues display similar NOESY cross-peaks as their homologs in SprG31. (B): Superposition of the 300ms NOESY spectra of SprG131 (black) and SprG131 (green) peptides recorded at $313 \mathrm{~K}$ and $\mathrm{pH} 4.5 \mathrm{in} 50 \% \mathrm{v} / \mathrm{v} \mathrm{d} 8$-isopropanol.

Author Contributions: Conceptualization, S.N.-L., B.F., and M.-L.P.-M.; methodology, S.N.-L. and L.F.; software, S.N.-L. and L.F.; writing—original draft preparation, S.N.-L., L.F., and M.-L.P.-M.; writing-review and editing, S.N.-L., L.F., and M.-L.P.-M.; supervision, S.N.-L., B.F., and M.-L.P.-M.; funding acquisition, S.N.-L., B.F. and M.-L.P.-M. All authors have read and agreed to the published version of the manuscript.

Funding: This work was funded by the Université de Rennes 1, the Université de Paris, the Centre National de la Recherche Scientifique (CNRS), the Institut National de la Santé et de la Recherche Médicale (Inserm) and the School of Pharmacy and Medical Sciences of Rennes. L.F. is the recipient of a fellowship funded by the French Ministère de l'Enseignement Supérieur et de la Recherche (grant MENRT).

Institutional Review Board Statement: Not applicable.

Informed Consent Statement: Not applicable.

Data Availability Statement: Not applicable.

Acknowledgments: We thank A. Bondon, S. Chevance, I. Nicolas, Y. Augagneur, and V. Cattoir for their advice and for proofreading the review.

Conflicts of Interest: The authors declare no conflict of interest.

\section{References}

1. Van Melderen, L.; Saavedra De Bast, M. Bacterial Toxin-Antitoxin Systems: More Than Selfish Entities? PLoS Genet. 2009, 5, e1000437. [CrossRef] [PubMed]

2. Pandey, D.P. Toxin-Antitoxin Loci Are Highly Abundant in Free-Living but Lost from Host-Associated Prokaryotes. Nucleic Acids Res. 2005, 33, 966-976. [CrossRef] [PubMed]

3. Wang, X.; Yao, J.; Sun, Y.-C.; Wood, T.K. Type VII Toxin/Antitoxin Classification System for Antitoxins That Enzymatically Neutralize Toxins. Trends Microbiol. 2021, 29, 388-393. [CrossRef] [PubMed]

4. Choi, J.S.; Kim, W.; Suk, S.; Park, H.; Bak, G.; Yoon, J.; Lee, Y. The Small RNA, SdsR, Acts as a Novel Type of Toxin in Escherichia Coli. RNA Biol. 2018, 15, 1319-1335. [CrossRef]

5. Jankevicius, G.; Ariza, A.; Ahel, M.; Ahel, I. The Toxin-Antitoxin System DarTG Catalyzes Reversible ADP-Ribosylation of DNA. Mol. Cell 2016, 64, 1109-1116. [CrossRef]

6. Lawarée, E.; Jankevicius, G.; Cooper, C.; Ahel, I.; Uphoff, S.; Tang, C.M. DNA ADP-Ribosylation Stalls Replication and Is Reversed by RecF-Mediated Homologous Recombination and Nucleotide Excision Repair. Cell Rep. 2020, 30, 1373-1384.e4. [CrossRef]

7. Lee, K.-Y.; Lee, B.-J. Structure, Biology, and Therapeutic Application of Toxin-Antitoxin Systems in Pathogenic Bacteria. Toxins 2016, 8, 305. [CrossRef]

8. Fozo, E.M.; Makarova, K.S.; Shabalina, S.A.; Yutin, N.; Koonin, E.V.; Storz, G. Abundance of Type I Toxin-Antitoxin Systems in Bacteria: Searches for New Candidates and Discovery of Novel Families. Nucleic Acids Res. 2010, 38, 3743-3759. [CrossRef]

9. Gerdes, K.; Bech, F.W.; Jørgensen, S.T.; Løbner-Olesen, A.; Rasmussen, P.B.; Atlung, T.; Boe, L.; Karlstrom, O.; Molin, S.; von Meyenburg, K. Mechanism of Postsegregational Killing by the Hok Gene Product of the ParB System of Plasmid R1 and Its Homology with the RelF Gene Product of the E. Coli RelB Operon. EMBO J. 1986, 5, 2023-2029. [CrossRef] 
10. Pedersen, K.; Gerdes, K. Multiple Hok Genes on the Chromosome of Escherichia Coli. Mol. Microbiol. 1999, $32,1090-1102$. [CrossRef]

11. Wen, J.; Fozo, E. SRNA Antitoxins: More than One Way to Repress a Toxin. Toxins 2014, 6, 2310-2335. [CrossRef]

12. Fisher, R.A.; Gollan, B.; Helaine, S. Persistent Bacterial Infections and Persister Cells. Nat. Rev. Microbiol. 2017, 15, 453-464. [CrossRef]

13. Masachis, S.; Darfeuille, F. Type I Toxin-Antitoxin Systems: Regulating Toxin Expression via Shine-Dalgarno Sequence Sequestration and Small RNA Binding. In Regulating with RNA in Bacteria and Archaea; Storz, G., Papenfort, K., Eds.; ASM Press: Washington, DC, USA, 2018; pp. 171-190. ISBN 978-1-68367-051-3.

14. Brantl, S.; Jahn, N. SRNAs in Bacterial Type I and Type III Toxin-Antitoxin Systems. FEMS Microbiol. Rev. 2015, 39, 413-427. [CrossRef]

15. Brielle, R.; Pinel-Marie, M.-L.; Felden, B. Linking Bacterial Type I Toxins with Their Actions. Curr. Opin. Microbiol. 2016, 30, 114-121. [CrossRef]

16. Guo, Y.; Quiroga, C.; Chen, Q.; McAnulty, M.J.; Benedik, M.J.; Wood, T.K.; Wang, X. RalR (a DNase) and RalA (a Small RNA) Form a Type I Toxin-Antitoxin System in Escherichia Coli. Nucleic Acids Res. 2014, 42, 6448-6462. [CrossRef]

17. Kawano, M.; Aravind, L.; Storz, G. An Antisense RNA Controls Synthesis of an SOS-Induced Toxin Evolved from an Antitoxin. Mol. Microbiol. 2007, 64, 738-754. [CrossRef]

18. Huan, Y.; Kong, Q.; Mou, H.; Yi, H. Antimicrobial Peptides: Classification, Design, Application and Research Progress in Multiple Fields. Front. Microbiol. 2020, 11, 582779. [CrossRef]

19. Steinbrecher, T.; Prock, S.; Reichert, J.; Wadhwani, P.; Zimpfer, B.; Bürck, J.; Berditsch, M.; Elstner, M.; Ulrich, A.S. Peptide-Lipid Interactions of the Stress-Response Peptide TisB That Induces Bacterial Persistence. Biophys. J. 2012, 103, 1460-1469. [CrossRef]

20. Mok, W.W.K.; Patel, N.H.; Li, Y. Decoding Toxicity. J. Biol. Chem. 2010, 285, 41627-41636. [CrossRef]

21. Göbl, C.; Dulle, M.; Hohlweg, W.; Grossauer, J.; Falsone, S.F.; Glatter, O.; Zangger, K. Influence of Phosphocholine Alkyl Chain Length on Peptide-Micelle Interactions and Micellar Size and Shape. J. Phys. Chem. B 2010, 114, 4717-4724. [CrossRef]

22. Göbl, C.; Kosol, S.; Stockner, T.; Rückert, H.M.; Zangger, K. Solution Structure and Membrane Binding of the Toxin Fst of the Par Addiction Module. Biochemistry 2010, 49, 6567-6575. [CrossRef]

23. Sayed, N.; Nonin-Lecomte, S.; Réty, S.; Felden, B. Functional and Structural Insights of a Staphylococcus Aureus Apoptotic-like Membrane Peptide from a Toxin-Antitoxin Module. J. Biol. Chem. 2012, 287, 43454-43463. [CrossRef] [PubMed]

24. Korkut, D.N.; Alves, I.D.; Vogel, A.; Chabas, S.; Sharma, C.M.; Martinez, D.; Loquet, A.; Salgado, G.F.; Darfeuille, F. Structural Insights into the AapA1 Toxin of Helicobacter Pylori. Biochim. Biophys. Acta (BBA) Gen. Subj. 2020, 1864, 129423. [CrossRef]

25. Scheglmann, D.; Werner, K.; Eiselt, G.; Klinger, R. Role of Paired Basic Residues of Protein C-Termini in Phospholipid Binding. Protein Eng. Des. Sel. 2002, 15, 521-527. [CrossRef] [PubMed]

26. Weaver, K.E.; Reddy, S.G.; Brinkman, C.L.; Patel, S.; Bayles, K.W.; Endres, J.L. Identification and Characterization of a Family of Toxin-Antitoxin Systems Related to the Enterococcus Faecalis Plasmid PAD1 Par Addiction Module. Microbiology 2009, 155, 2930-2940. [CrossRef]

27. Drozdetskiy, A.; Cole, C.; Procter, J.; Barton, G.J. JPred4: A Protein Secondary Structure Prediction Server. Nucleic Acids Res. 2015, 43, W389-W394. [CrossRef] [PubMed]

28. Osorio, D.; Rondón-Villarreal, P.; Torres, R. Peptides: A Package for Data Mining of Antimicrobial Peptides. R J. 2015, 7, 4. [CrossRef]

29. Kyte, J.; Doolittle, R.F. A Simple Method for Displaying the Hydropathic Character of a Protein. J. Mol. Biol. 1982, 157, 105-132. [CrossRef]

30. Unoson, C.; Wagner, E.G.H. A Small SOS-Induced Toxin Is Targeted against the Inner Membrane in Escherichia Coli: Mode of Action of TisB. Mol. Microbiol. 2008, 70, 258-270. [CrossRef]

31. Thisted, T.; Sørensen, N.S.; Wagner, E.G.; Gerdes, K. Mechanism of Post-Segregational Killing: Sok Antisense RNA Interacts with Hok MRNA via Its 5'-End Single-Stranded Leader and Competes with the $3^{\prime}$-End of Hok MRNA for Binding to the Mok Translational Initiation Region. EMBO J. 1994, 13, 1960-1968. [CrossRef]

32. Verstraeten, N.; Knapen, W.J.; Kint, C.I.; Liebens, V.; Van den Bergh, B.; Dewachter, L.; Michiels, J.E.; Fu, Q.; David, C.C.; Fierro, A.C.; et al. Obg and Membrane Depolarization Are Part of a Microbial Bet-Hedging Strategy That Leads to Antibiotic Tolerance. Mol. Cell 2015, 59, 9-21. [CrossRef]

33. Verstraeten, N.; Gkekas, S.; Kint, C.I.; Deckers, B.; Van den Bergh, B.; Herpels, P.; Louwagie, E.; Knapen, W.; Wilmaerts, D.; Dewachter, L.; et al. Biochemical Determinants of ObgE-mediated Persistence. Mol. Microbiol. 2019, 112, 1593-1608. [CrossRef]

34. Wilmaerts, D.; Bayoumi, M.; Dewachter, L.; Knapen, W.; Mika, J.T.; Hofkens, J.; Dedecker, P.; Maglia, G.; Verstraeten, N.; Michiels, J. The Persistence-Inducing Toxin HokB Forms Dynamic Pores That Cause ATP Leakage. mBio 2018, 9, e00744-18. [CrossRef]

35. Edelmann, D.; Berghoff, B.A. Type I Toxin-Dependent Generation of Superoxide Affects the Persister Life Cycle of Escherichia Coli. Sci. Rep. 2019, 9, 14256. [CrossRef]

36. Wilmaerts, D.; Dewachter, L.; De Loose, P.-J.; Bollen, C.; Verstraeten, N.; Michiels, J. HokB Monomerization and Membrane Repolarization Control Persister Awakening. Mol. Cell 2019, 75, 1031-1042.e4. [CrossRef]

37. Argaman, L.; Hershberg, R.; Vogel, J.; Bejerano, G.; Wagner, E.G.H.; Margalit, H.; Altuvia, S. Novel Small RNA-Encoding Genes in the Intergenic Regions of Escherichia Coli. Curr. Biol. 2001, 11, 941-950. [CrossRef] 
38. Wassarman, K.M. Identification of Novel Small RNAs Using Comparative Genomics and Microarrays. Genes Dev. 2001, 15, 1637-1651. [CrossRef]

39. Vogel, J.; Argaman, L.; Wagner, E.G.H.; Altuvia, S. The Small RNA IstR Inhibits Synthesis of an SOS-Induced Toxic Peptide. Curr. Biol. 2004, 14, 2271-2276. [CrossRef]

40. Maslowska, K.H.; Makiela-Dzbenska, K.; Fijalkowska, I.J. The SOS System: A Complex and Tightly Regulated Response to DNA Damage. Environ. Mol. Mutagen. 2019, 60, 368-384. [CrossRef]

41. Darfeuille, F.; Unoson, C.; Vogel, J.; Wagner, E.G.H. An Antisense RNA Inhibits Translation by Competing with Standby Ribosomes. Mol. Cell 2007, 26, 381-392. [CrossRef]

42. Dörr, T.; Vulić, M.; Lewis, K. Ciprofloxacin Causes Persister Formation by Inducing the TisB Toxin in Escherichia Coli. PLoS Biol. 2010, 8, e1000317. [CrossRef] [PubMed]

43. Berghoff, B.A.; Hoekzema, M.; Aulbach, L.; Wagner, E.G.H. Two Regulatory RNA Elements Affect TisB-Dependent Depolarization and Persister Formation: RNA-Based Regulation of Depolarization and Persistence. Mol. Microbiol. 2017, 103, 1020-1033. [CrossRef] [PubMed]

44. Edelmann, D.; Oberpaul, M.; Schäberle, T.F.; Berghoff, B.A. Post-transcriptional Deregulation of the tisB/istR-1 Toxin-Antitoxin System Promotes SOS -independent Persister Formation in Escherichia coli. Environ. Microbiol. Rep. 2021, 13, 159-168. [CrossRef] [PubMed]

45. Gurnev, P.A.; Ortenberg, R.; Dörr, T.; Lewis, K.; Bezrukov, S.M. Persister-Promoting Bacterial Toxin TisB Produces Anion-Selective Pores in Planar Lipid Bilayers. FEBS Lett. 2012, 586, 2529-2534. [CrossRef]

46. Sayed, N.; Jousselin, A.; Felden, B. A Cis-Antisense RNA Acts in Trans in Staphylococcus Aureus to Control Translation of a Human Cytolytic Peptide. Nat. Struct. Mol. Biol. 2012, 19, 105-112. [CrossRef]

47. Pichon, C.; Felden, B. From The Cover: Small RNA Genes Expressed from Staphylococcus Aureusgenomic and Pathogenicity Islands with Specific Expression among Pathogenic Strains. Proc. Natl. Acad. Sci. USA 2005, 102, 14249-14254. [CrossRef]

48. Solecki, O.; Mosbah, A.; Baudy Floc'h, M.; Felden, B. Converting a Staphylococcus Aureus Toxin into Effective Cyclic Pseudopeptide Antibiotics. Chem. Biol. 2015, 22, 329-335. [CrossRef]

49. Weaver, K. The Fst/Ldr Family of Type I TA System Toxins: Potential Roles in Stress Response, Metabolism and Pathogenesis. Toxins 2020, 12, 474. [CrossRef]

50. Folli, C.; Levante, A.; Percudani, R.; Amidani, D.; Bottazzi, S.; Ferrari, A.; Rivetti, C.; Neviani, E.; Lazzi, C. Toward the Identification of a Type I Toxin-Antitoxin System in the Plasmid DNA of Dairy Lactobacillus Rhamnosus. Sci. Rep. $2017,7,12051$. [CrossRef]

51. Maggi, S.; Yabre, K.; Ferrari, A.; Lazzi, C.; Kawano, M.; Rivetti, C.; Folli, C. Functional Characterization of the Type I Toxin Lpt from Lactobacillus Rhamnosus by Fluorescence and Atomic Force Microscopy. Sci. Rep. 2019, 9, 15208. [CrossRef]

52. Weaver, K.E. The Par Toxin-Antitoxin System from Enterococcus Faecalis Plasmid PAD1 and Its Chromosomal Homologs. RNA Biol. 2012, 9, 1498-1503. [CrossRef]

53. Wen, J.; Harp, J.R.; Fozo, E.M. The 5' UTR of the Type I Toxin ZorO Can Both Inhibit and Enhance Translation. Nucleic Acids Res. 2017, 45, 4006-4020. [CrossRef]

54. Otsuka; Ishikawa; Takahashi; Masuda A Short Peptide Derived from the ZorO Toxin Functions as an Effective Antimicrobial. Toxins 2019, 11, 392. [CrossRef]

55. Rudd, K.E. Novel Intergenic Repeats of Escherichia Coli K-12. Res. Microbiol. 1999, 150, 653-664. [CrossRef]

56. Fozo, E.M.; Kawano, M.; Fontaine, F.; Kaya, Y.; Mendieta, K.S.; Jones, K.L.; Ocampo, A.; Rudd, K.E.; Storz, G. Repression of Small Toxic Protein Synthesis by the Sib and OhsC Small RNAs. Mol. Microbiol. 2008, 70, 1076-1093. [CrossRef]

57. Han, K.; Kim, K.; Bak, G.; Park, H.; Lee, Y. Recognition and Discrimination of Target MRNAs by Sib RNAs, a Cis-Encoded SRNA Family. Nucleic Acids Res. 2010, 38, 5851-5866. [CrossRef]

58. Manganelli, R.; Gennaro, M.L. Protecting from Envelope Stress: Variations on the Phage-Shock-Protein Theme. Trends Microbiol. 2017, 25, 205-216. [CrossRef]

59. Fozo, E.M. New Type I Toxin-Antitoxin Families from “Wild" and Laboratory Strains of E. Coli: Ibs-Sib, ShoB-OhsC and Zor-Orz. RNA Biol. 2012, 9, 1504-1512. [CrossRef]

60. Yamaguchi, Y.; Tokunaga, N.; Inouye, M.; Phadtare, S. Characterization of LdrA (Long Direct Repeat A) Protein of Escherichia Coli. J. Mol. Microbiol. Biotechnol. 2014, 24, 91-97. [CrossRef]

61. Fernández de Henestrosa, A.R.; Ogi, T.; Aoyagi, S.; Chafin, D.; Hayes, J.J.; Ohmori, H.; Woodgate, R. Identification of Additional Genes Belonging to the LexA Regulon in Escherichia Coli: Novel LexA-Regulated Genes in E. Coli. Mol. Microbiol. 2002, 35, 1560-1572. [CrossRef]

62. Weel-Sneve, R.; Kristiansen, K.I.; Odsbu, I.; Dalhus, B.; Booth, J.; Rognes, T.; Skarstad, K.; Bjørås, M. Single Transmembrane Peptide DinQ Modulates Membrane-Dependent Activities. PLoS Genet. 2013, 9, e1003260. [CrossRef]

63. Kristiansen, K.I.; Weel-Sneve, R.; Booth, J.A.; Bjørås, M. Mutually Exclusive RNA Secondary Structures Regulate Translation Initiation of DinQ in Escherichia Coli. RNA 2016, 22, 1739-1749. [CrossRef]

64. Berghoff, B.A.; Wagner, E.G.H. RNA-Based Regulation in Type I Toxin-Antitoxin Systems and Its Implication for Bacterial Persistence. Curr. Genet. 2017, 63, 1011-1016. [CrossRef] 
65. Weaver, K.E.; Walz, K.D.; Heine, M.S. Isolation of a Derivative OfEscherichia Coli-Enterococcus FaecalisShuttle Vector PAM401 Temperature Sensitive for Maintenance InE. Faecalisand Its Use in Evaluating the Mechanism of PAD1par-Dependent Plasmid Stabilization. Plasmid 1998, 40, 225-232. [CrossRef]

66. Greenfield, T.J.; Ehli, E.; Kirshenmann, T.; Franch, T.; Gerdes, K.; Weaver, K.E. The Antisense RNA of the Par Locus of PAD1 Regulates the Expression of a 33-Amino-Acid Toxic Peptide by an Unusual Mechanism: PAD1 Par Stability Function. Mol. Microbiol. 2002, 37, 652-660. [CrossRef]

67. Greenfield, T.J.; Franch, T.; Gerdes, K.; Weaver, K.E. Antisense RNA Regulation of the Par Post-Segregational Killing System: Structural Analysis and Mechanism of Binding of the Antisense RNA, RNAII and Its Target, RNAI. Mol. Microbiol. 2001, 42, 527-537. [CrossRef]

68. Shokeen, S.; Patel, S.; Greenfield, T.J.; Brinkman, C.; Weaver, K.E. Translational Regulation by an Intramolecular Stem-Loop Is Required for Intermolecular RNA Regulation of the Par Addiction Module. JB 2008, 190, 6076-6083. [CrossRef]

69. Shokeen, S.; Greenfield, T.J.; Ehli, E.A.; Rasmussen, J.; Perrault, B.E.; Weaver, K.E. An Intramolecular Upstream Helix Ensures the Stability of a Toxin-Encoding RNA in Enterococcus Faecalis. JB 2009, 191, 1528-1536. [CrossRef]

70. Patel, S.; Weaver, K.E. Addiction Toxin Fst Has Unique Effects on Chromosome Segregation and Cell Division in Enterococcus Faecalis and Bacillussubtilis. JB 2006, 188, 5374-5384. [CrossRef]

71. Weaver, K.E.; Weaver, D.M.; Wells, C.L.; Waters, C.M.; Gardner, M.E.; Ehli, E.A. Enterococcus Faecalis Plasmid PAD1-Encoded Fst Toxin Affects Membrane Permeability and Alters Cellular Responses to Lantibiotics. JB 2003, 185, 2169-2177. [CrossRef]

72. Brinkman, C.L.; Bumgarner, R.; Kittichotirat, W.; Dunman, P.M.; Kuechenmeister, L.J.; Weaver, K.E. Characterization of the Effects of an RpoC Mutation That Confers Resistance to the Fst Peptide Toxin-Antitoxin System Toxin. J. Bacteriol. 2013, 195, 156-166. [CrossRef] [PubMed]

73. Jahn, N.; Preis, H.; Wiedemann, C.; Brantl, S. BsrG/SR4 from Bacillus Subtilis- the First Temperature-Dependent Type I ToxinAntitoxin System: BsrG/SR4 - Toxin-Antitoxin System in B. Subtilis. Mol. Microbiol. 2012, 83, 579-598. [CrossRef] [PubMed]

74. Jahn, N.; Brantl, S. One Antitoxin-Two Functions: SR4 Controls Toxin MRNA Decay and Translation. Nucleic Acids Res. 2013, 41, 9870-9880. [CrossRef] [PubMed]

75. Jahn, N.; Brantl, S.; Strahl, H. Against the Mainstream: The Membrane-Associated Type I Toxin BsrG from B Acillus Subtilis Interferes with Cell Envelope Biosynthesis without Increasing Membrane Permeability: Cellular Toxicity of B. Subtilis Type I Toxin BsrG. Mol. Microbiol. 2015, 98, 651-666. [CrossRef]

76. Brantl, S.; Müller, P. Toxin-Antitoxin Systems in Bacillus Subtilis. Toxins 2019, 11, 262. [CrossRef]

77. Sharma, C.M.; Hoffmann, S.; Darfeuille, F.; Reignier, J.; Findeiß, S.; Sittka, A.; Chabas, S.; Reiche, K.; Hackermüller, J.; Reinhardt, R.; et al. The Primary Transcriptome of the Major Human Pathogen Helicobacter Pylori. Nature 2010, 464, $250-255$. [CrossRef]

78. Arnion, H.; Korkut, D.N.; Masachis Gelo, S.; Chabas, S.; Reignier, J.; Iost, I.; Darfeuille, F. Mechanistic Insights into Type I Toxin Antitoxin Systems in Helicobacter Pylori: The Importance of MRNA Folding in Controlling Toxin Expression. Nucleic Acids Res. 2017, 45, 4782-4795. [CrossRef]

79. El Mortaji, L.; Tejada-Arranz, A.; Rifflet, A.; Boneca, I.G.; Pehau-Arnaudet, G.; Radicella, J.P.; Marsin, S.; De Reuse, H. A Peptide of a Type I Toxin-antitoxin System Induces Helicobacter Pylori Morphological Transformation from Spiral Shape to Coccoids. Proc. Natl. Acad. Sci. USA 2020, 117, 31398-31409. [CrossRef]

80. Kawano, M.; Oshima, T.; Kasai, H.; Mori, H. Molecular Characterization of Long Direct Repeat (LDR) Sequences Expressing a Stable MRNA Encoding for a 35-Amino-Acid Cell-Killing Peptide and a Cis-Encoded Small Antisense RNA in Escherichia Coli. Mol. Microbiol. 2002, 45, 333-349. [CrossRef]

81. Pinel-Marie, M.-L.; Brielle, R.; Felden, B. Dual Toxic-Peptide-Coding Staphylococcus Aureus RNA under Antisense Regulation Targets Host Cells and Bacterial Rivals Unequally. Cell Rep. 2014, 7, 424-435. [CrossRef]

82. Pinel-Marie, M.-L.; Brielle, R.; Riffaud, C.; Germain-Amiot, N.; Polacek, N.; Felden, B. RNA Antitoxin SprF1 Binds Ribosomes to Attenuate Translation and Promote Persister Cell Formation in Staphylococcus Aureus. Nat. Microbiol. 2021, 6, 209-220. [CrossRef]

83. Krantz, B.A. A Phenylalanine Clamp Catalyzes Protein Translocation through the Anthrax Toxin Pore. Science 2005, 309, 777-781. [CrossRef]

84. Li, S.; Wang, Y.; Xue, Z.; Jia, Y.; Li, R.; He, C.; Chen, H. The Structure-Mechanism Relationship and Mode of Actions of Antimicrobial Peptides: A Review. Trends Food Sci. Technol. 2021, 109, 103-115. [CrossRef]

85. Alix, E.; Blanc-Potard, A.-B. Hydrophobic Peptides: Novel Regulators within Bacterial Membrane: Regulatory Membrane Peptides in Bacteria. Mol. Microbiol. 2009, 72, 5-11. [CrossRef]

86. Cheng, H.-Y.; Soo, V.W.C.; Islam, S.; McAnulty, M.J.; Benedik, M.J.; Wood, T.K. Toxin GhoT of the GhoT/GhoS Toxin/Antitoxin System Damages the Cell Membrane to Reduce Adenosine Triphosphate and to Reduce Growth under Stress: GhoT Damages the Membrane to Increase Resistance. Environ. Microbiol. 2014, 16, 1741-1754. [CrossRef]

87. Nicolas, I.; Bordeau, V.; Bondon, A.; Baudy-Floc'h, M.; Felden, B. Novel Antibiotics Effective against Gram-Positive and -Negative Multi-Resistant Bacteria with Limited Resistance. PLoS Biol. 2019, 17, e3000337. [CrossRef]

88. Booth, J.A.; Suganthan, R.; Gaustad, P.; Bjørås, M. Development of DinQ from Escherichia Coli as an Anti-Cell-Envelope Antibiotic. Int. J. Antimicrob. Agents 2015, 45, 196-197. [CrossRef] 